\title{
Biotechnology of Floricultural Crops
}

\author{
William R. Woodson \\ Department of Horticulture, Purdue University, West Lafayette, IN 47907
}

\begin{abstract}
The production and use of floricultural crops represents an expanding area in U.S. agriculture. Currently, the wholesale value of the U.S. floriculture industry exceeds 2 billion dollars. The production of plants solely for their aesthetic value represents a unique form of agriculture. As a result of their ornamental value, efforts to improve flower crops center around quality attributes such as flower color, flower form, plant architecture, and postharvest keeping quality (vase life). In addition, improved agronomic traits, such as disease and insect resistance, are sought in flower breeding programs, as with other crop species. Traditionally, the breeding of flower crops has been more art than science. Typically, breeders will cross two plants with little knowledge of their genetic makeup and screen the resulting progeny for desirable characteristics. The parents of such a cross are often heterozygous, thus resulting in a myriad of phenotypes in the seedling population. It is for this reason that selections are maintained through vegetative propagation to ensure genetically identical individuals. Due to the high value of flower crops, it is economically feasible to propagate plants vegetatively rather than by the less expensive seed propagation method. Clearly, most flower breeding programs are less sophisticated than those for agronomic crops, where inbred lines of known genetic makeup exist. While such an approach has yielded many valuable flower cultivars, it certainly has its limitations. The extreme heterozygosity in many valuable floricultural crops (rose, chrysanthemum, and carnation) limits the advances in breeding. For example, as a result of the lack of inbred lines, directed breeding efforts for individual traits are very difficult. In addition, the improvement of flower crops by traditional breeding is hampered by a limited gene pool. Certainly, this is an explanation for the lack of desirable blue pigments in roses and carnations.
\end{abstract}

\section{GENETIC ENGINEERING FOR THE IMPROVEMENT OF FLORICULTURAL CROPS}

Recent advances in the isolation, characterization, and transfer of genes between species makes genetic engineering an attractive technology to be used in conjunction with traditional breeding for the improvement of flower crops. Certainly, genetic engineering has the capability of increasing the gene pool available for crop improvement. Thus, genes conferring desirable traits, such as blue pigmentation, potentially can be transferred to species where these genes previously did not exist. An advantage of such a genetic engineering approach lies in the ability to alter a single trait without altering other genetic traits of the plant. Therefore, a much more directed approach to flower crop improvement is possible using these techniques. Currently, the major limitations in the use of genetic engineering to improve flower crops include: 1) the identification and isolation of genes conferring desirable traits and 2) the development of efficient techniques for transformation of important flower crop species.

The insertion and stable integration of foreign DNA into plant cells is becoming routine for several species. Transformation of plants is generally accomplished by two techniques. These include the use of Agrobacterium tumefaciens as a natural gene transfer system and the delivery of free DNA into plant cells. It is beyond the scope of this paper to review in detail these transformation techniques, which are covered by several excellent reviews (Gasser and Fraley, 1989; Klee et al., 1987; Schell; 1987). To date, petunia is the only floricultural crop that is routinely transformed using

Publication no. 12,270 of the Purdue Univ. Agricultural Experiment Station. Our research on flower senescence was supported by grants from the National Science Foundation \#DCB-8911205, the Fred C. Gloeckner Foundation, and the Indiana Corp. for Science and Technology.
Agrobacterium (Gasser and Fraley, 1989). Current efforts are aimed at developing techniques for high-value flower crops, such as carnation (R. Woodson, A. Brandt, and P. Goldsbrough, unpublished results), chrysanthemum, and roses. It is expected that early successes in flower crop genetic engineering will occur in these species. Much of these efforts involve several plant biotechnology companies in the United States, Europe, and Australia. Transformation technology is developing at such a pace that insertion of DNA into most plants should be routine in a few years. This is particularly true with the recent development of the free DNA delivery technique of particle bombardment (McCabe et al., 1988). Given the advances in this technology, it is clear that much of the current research emphasis should be placed on the isolation and characterization of genes controlling desirable traits for the improvement of flower crops.

\section{TARGETS FOR IMPROVEMENT OF FLOWER CROPS BY GENETIC ENGINEERING}

\section{Production efficiency}

The ability to transform flower crop species efficiently will result in the desire to use this technology to improve these crops. Most likely, initial efforts in this regard will focus on the use of previously identified and characterized genes that control general agronomic traits, such as disease and insect resistance. Progress in these areas has been rapid, particularly with regard to insect resistance. The transfer and expression of insect control protein genes from Bacillus thuringiensis (Bt) has resulted in an increased resistance to lepidopteran larvae (Fischhoff et al., 1987; McPherson, 1988; Vaek et al., 1987). The advantage of the $B t$ toxin is in its insect specificity, with the protein exhibiting limited toxicity to other insects and no toxicity to animals, including humans. In addition to the $B t$ toxin gene, recent tests have shown that the expression of a cowpea trypsin inhibitor gene in transgenic tobacco resulted in resistance to herbivorous insect pests (Hilder et al., 1988). Clearly, the isolation and characterization of other natural insecticidal molecules will result in new genetic engineering approaches to the improvement of insect resistance in crop plants.

One of the most exciting advances in biotechnology is the potential for genetically engineering virus resistance in plants. Losses of flower crops due to virus infection are severe, especially given the cultural practices of vegetative propagation and extensive pruning. This resistance is often referred to as "coat protein-mediated" protection and involves the transfer of the coding region for the coat protein of a given virus to the target crop (Abel et al., 1986). The expression of the coat protein gene of tobacco mosaic virus (TMV) in transgenic tomato plants resulted in substantial resistance to infection by the TMV virus (Abel et al., 1986). A similar approach has resulted in resistance to various plant viruses, including cucumber mosaic virus (Hoekema et al., 1989) and alfalfa mosaic virus (Turner et al., 1987). The availability of cloned and sequenced plant viruses will undoubtedly extend the use of this technology to the protection of flower crops against viral infection.

Only limited success has been reported in the area of resistance to fungal diseases through genetic engineering. Recently, Broglie et al. (1989) reported on the cloning and characterization of a gene for chitinase from beans. Chitinase is a protein that hydrolyzes chitin, a component of fungal cell walls, and is believed to play a role in the plant's defense against fungal attack. Indeed, this enzyme has been shown to inhibit the growth of fungi in vitro (Schlumbaum et al., 1986). Recently, Broekaert et al. (1989) reported that a purified, chitinase-free plant lectin showed antifungal properties. 
The expression of genes encoding such antifungal proteins may increase the plant's resistance to fungal attack.

\section{Quality improvement}

Flower crops are marketed based on their ornamental value. The color and form of the flower, the architecture of the plant, and the postproduction life of the flower are all viable targets for improvement by genetic engineering. Certainly the identification of genes controlling these traits will be of great importance in the improvement of flower crops. The following is a summary of current research, much of which uses "model" systems to identify genes that control several traits targeted for improving flower crops.

Flower color. The floriculture industry is driven by the availability of novel flower crops. In recent years, flower markets worldwide have seen increasing demand for unusual plants, frequently imported from foreign countries. Because of this desire for novel flowers, there is tremendous interest in using genetic engineering to introduce genes for new flower colors. This is particularly true for rare shades of blue and purple, which are absent in many of the major flower crops.

The most common compounds resulting in flower pigmentation are flavonoids. While carotenoids lead to pigmentation in severa flowers, much less is known about the genes involved in this pathway as compared to that of anthocyanins. As a result of extensive research into the genetics of anthocyanin biosynthesis using maize (Dooner, 1983), petunia (de Vlaming et al., 1984), and Antirrhinum (Martin et al., 1987), much is known about the genes encoding enzymes of this pathway. The basic anthocyanin biosynthesis pathway is illustrated in Fig. 1. The first published reports of modifying flower pigmentation by genetic engineering involve the manipulation of this pathway. A research group at the Max-Planck Inst., Germany, successfully created a novel flower color in petunia by inserting a gene from maize (Meyer et al., 1987). In petunia, cyanidin and delphinidin derivatives, but no pelargonidin derivatives, are produced as pigments, apparently because the enzyme dihydroflavonol 4-reductase shows substrate specificity and cannot reduce dihydrokaempferol, leading to the production of pelargonidin. The Al gene from maize (Schwarz-Somner et al., 1987) encodes dihydroquercetin 4-reductase, which normally converts dihydroquercetin into leucocyanidin, thus leading to the production of cyanidin derivatives. However, this enzyme does not show the same substrate specificity as does the petunia enzyme. These researchers transformed a mutant petunia line (RL01) that accumulates dihydrokaempferol and, thus, shows no pigmentation. They inserted the

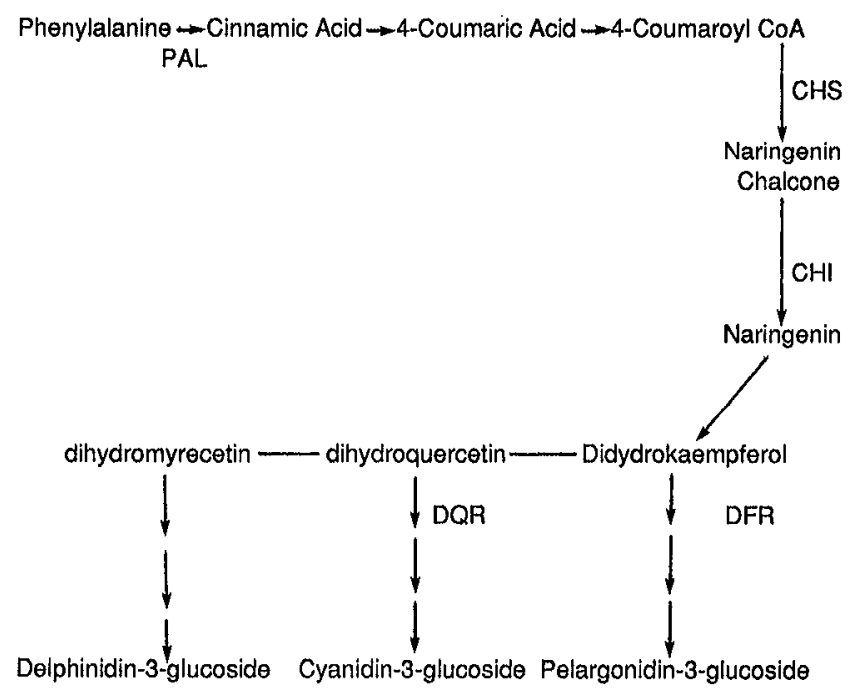

Fig. 1. The flavonoid biosynthetic pathway. Enzymes are: phenylalanine ammonia lyase (PAL); chalcone synthase (CHS); chalcone isomerase (CHI); dihydroflavonol-4-reductase (DFR); and dihydroquercetin 4-reductase (DQR). Pigmentation occurs only in the presence of naringenin chalcone (yellow), pelargonidin derivatives (orange-red), cyanidin derivatives (scarlet red), and delphinidin derivatives (purple-blue). maize AI gene as a chimeric gene construct using the CaMV $35 \mathrm{~S}$ promoter. The overexpression $A l$ gene from maize, coupled with the abundant substrate petunia mutation, resulted in the synthesis of pelargonidin deribatives and a novel brick-red pigmentation.

Another genetic engineering approach to modifying flower color is to reduce the expression of endogenous pigment biosynthesis genes, thus altering the pattern of pigmentation. This has recently been accomplished in petunia using a technique referred to as antisense RNA (van der Krol et al., 1988). This procedure involves the insertion of a reverse orientation copy of the endogenous gene (Fig. 2). The expression of this inserted gene gives rise to a complementary mRNA or antisense RNA strand that forms a duplex with the sense strand. This duplex likely is unstable and is not available for translation. The approach of the Dutch group was to insert and express an antisense chalcone synthase (Fig. 1) gene in petunia. They reported that this procedure had dramatic effects on the pigmentation of the normally red variety of petunia. When the endogenous chalcone synthase gene was completely inhibited, no coloration would be expected since the substrate for this enzyme is colorless. As expected, such plants were observed. However, unexpectedly, they also found pigmentation patterns as a result of antisense gene expression, suggesting some developmental regulation. The reason for these patterns is unclear. These examples of initial success in the genetic engineering of flower color certainly give reason to believe that in the not too distant future other novel colors will be created in flower crops.

Plant architecture. The manipulation of plant form and architecture by genetic engineering could have a tremendous impact on the floriculture industry. The identification of genes controlling developmental processes such as plant height and leaf and flower shape would contribute not only to our basic understanding of plant growth and development, but also would be potentially useful in the manipulation of plant form for flower crop improvement. Several genes controlling flower morphology have been identified by mutations in petunia (de Vlaming et al., 1984) Arabidopsis (Meyerowits, 1989), and Antirrhinum (Coen and Carpenter, 1986). Many of these genes direct developemental processes, such as petal number and petal shape, which could be potentially important for plant improvement. While these genes have been identified through the genetic

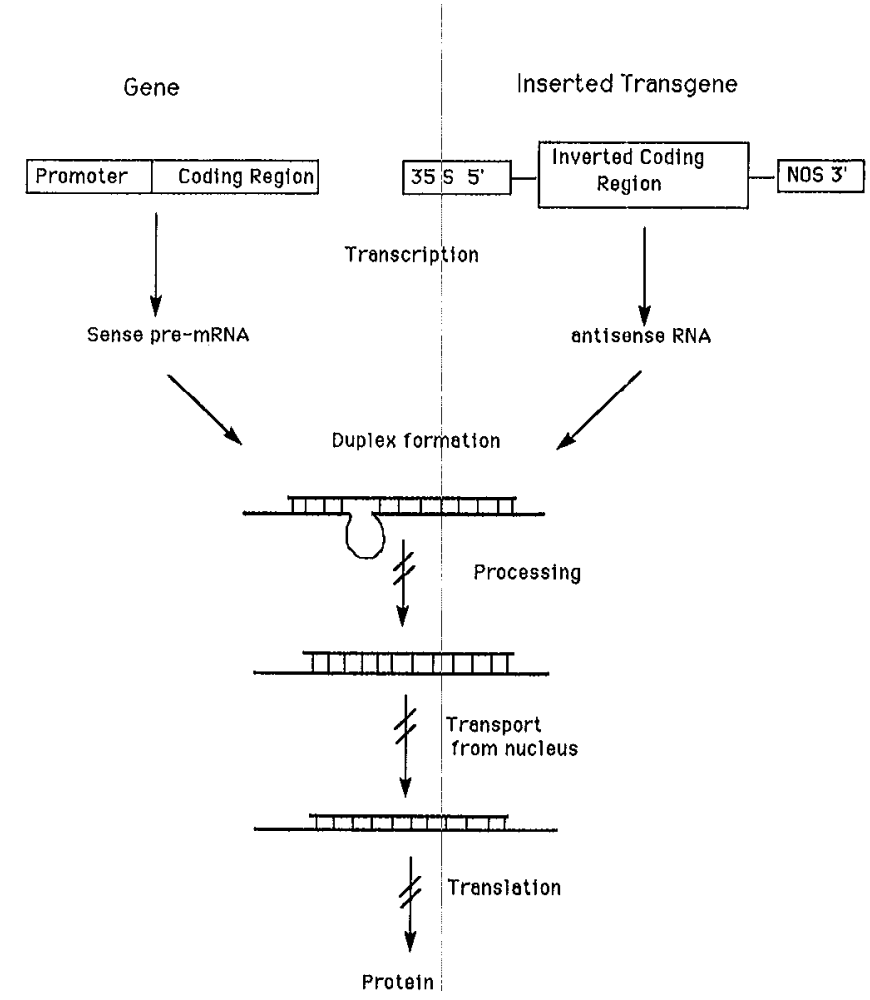

Fig. 2. Inhibition of gene expression by antisense RNA. Possible sites of inhibition. 
analysis of mutations, their cloning and isolation will prove difficult. Clearly, the greatest potential for isolating these genes is through the use of Arabidopsis. Because of its small genome, Arabidopsis is well suited for the identification of genes through mutation and the subsequent isolation of the mutated gene by gene tagging or chromosome walking (Meyerowitz, 1989). Recently, Feldman et al. (1989) reported on the mutation and tagging of genes in Arabidopsis by the random insertion of T-DNA into the plant genome as mediated by Agrobacterium transformation. This process offers a unique opportunity to isolate a mutated gene by virtue of the presence of T-DNA sequences. Using this process, they have identified several interesting mutants, including a dwarf plant architecture mutant. Of course, the control of plant height is of great importance in flower crop production. It is also possible to identify and isolate genes from Arabidopsis by chromosome walking due to the small genome. This effort will be aided by the recent development of an extensive genetic map of the Arabidopsis genome (Chang et al., 1988; Nam et al., 1989).

Molecular biology of flowering. The control of the flowering process is critical in the production of many floricultural crops. Indeed, research conducted in the $50 \mathrm{~s}$ and $60 \mathrm{~s}$ by floricultural scientists not only resulted in the development of procedures for controlled flowering of many flower crops, but also contributed to our basic understanding of the physiology of flowering. Several researchers recently have initiated studies on the molecular mechanisms underlying the regulation of flowering. Pharbitis nil is a short-day plant that has served as a model for photoperiodic induction of flowering (Vince-Prue and Gressel, 1986). Pharbitis nil seedlings are receptive to short-day induction in the seedling stage, with the cotyledons serving as the photoreceptive tissue (O'Neill, 1989). The short-day inductive treatment was recently shown to be associated with changes in gene expression based on the appearance of a new mRNA encoding a $28 \mathrm{kDa}$ polypeptide in the induced cotyledons (Lay-Yee et al., 1987). Efforts to clone genes potentially involved in the perception and transduction of the flowering stimulus are underway (O’Neill, 1989).

Another intense area of research on the molecular biology of flowering involves the characterization of those genes that play a role in the transition from vegetative to floral development. Re-

\section{SCREENING CDNA LIBRARY}

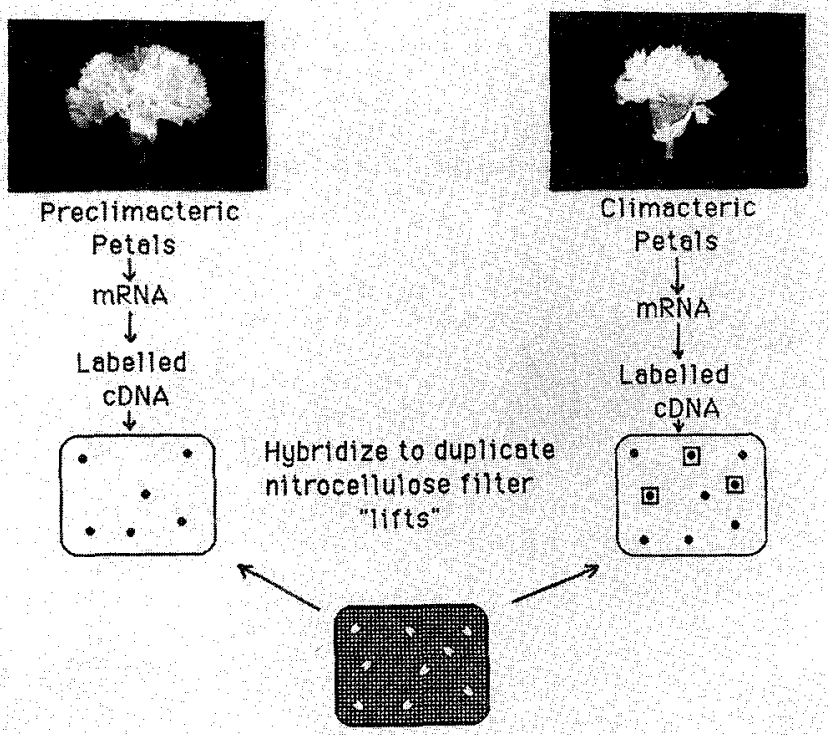

Recombinant phage plaques

Fig. 3. Schematic representation of differential hybridization approach to screening a petal senescence cDNA library for senescence-related cDNA clones. A portion of the Agt10 library is plated out and duplicate nitrocellulose filter lifts taken. These lifts are hybridized with ${ }^{32} \mathrm{P}$-labeled cDNA synthesized from mRNA isolated from preclimacteric or climacteric petals. Those plaques hybridizing specifically to cDNA from senescent petals were picked as containing senescence-related cDNA inserts. cently, Meek-Wagner et al. (1989) have taken advantage of the tobacco "thin cell layer" system of Tran Thanh Van (1973), in which hormone manipulation results in direct flower formation, to isolate genes expressed specifically in tissue during flower development. They reported the isolation of several cDNAs that represent mRNAs expressed in thin cell layer explants undergoing flower initiation and not in explants undergoing the initiation of vegetative structures. Furthermore, they found that these genes occur at low levels in several plant organs and at high levels in the roots of tobacco plants, with maximum expression in roots occurring just before the formation of floral meristems. While the role of these genes is not currently understood, the pattern of their expression indicates a role in flower development. The expression of floralspecific genes in the roots of tobacco plants is particularly interesting, given the evidence of the roots' role in flower formation in this plant (McDaniel, 1980).

Flower longevity. The postharvest longevity of flowers is of critical importance in determining the value of the crop. This is particularly true, given the global nature of the flower industry and the necessity for lengthy handling and transportation times. Research in postharvest physiology of flower crops (Borochov and Woodson, 1989; Halevy and Mayak, 1979, 1981), coupled with effective education programs, such as the "Chain of Life," has resulted in vast improvements in the longevity of flower crops. The discovery that in several cases flower senescence is regulated by the phytohormone ethylene has lead to the identification and use of chemicals, such as silver thiosulfate, which inhibits ethylene action and delays senescence (for review see Borochov and Woodson, 1989; Halevy and Mayak, 1981). Development of new treatments that delay senescence or of new cultivars with improved postharvest longevity is currently limited by our basic understanding of the molecular events underlying the regulation of flower senescence.

It is clear that flower senescence is a highly regulated developmental event requiring active gene expression and protein synthesis (Lawton et al., 1989; Woodson and Handa, 1987). Identification of genes involved in the regulation of senescence could result in the development of genetic engineering strategies to control senescence. I have chosen to study the molecular biology of flower senescence in carnation since much is known about the biology and physiology of senescence in this plant. Previously, I reported that the senescence of carnation petals is associated with both the ap-

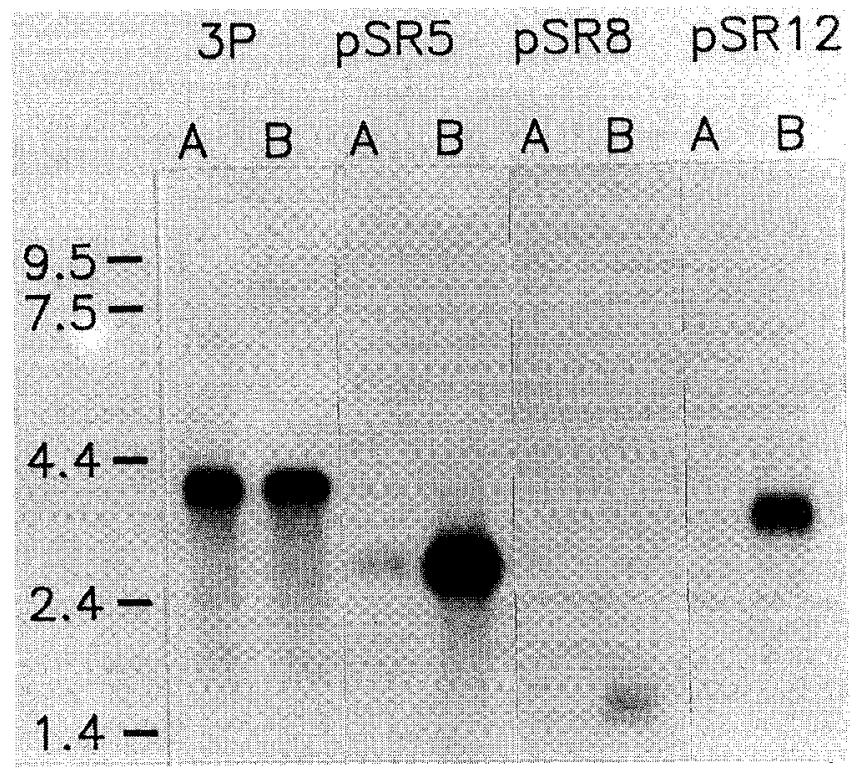

Fig. 4. Northern blot analysis of senescence-related mRNA abundance. One-microgram poly $(\mathrm{A}+) \mathrm{RNA}$ portions isolated from flower petals at anthesis (lane A) or at the climacteric (lane B) were separated electrophoretically under denaturing conditions, transferred to nitrocellulose, and hybridized with various CDNA clones. RNA size markers are shown in kilobases $(\mathrm{Kb})$ to the left of sample RNAs (from Lawton et al., 1989). 
pearance and disappearance of several polypeptides (Woodson, 1987). The isolation and in vitro translation of mRNAs at different stages of petal development revealed that the onset of senescence is associated with changes in gene expression, including the appearance of new mRNAs (Woodson, 1987). Furthermore, similar changes in mRNA populations occurred in young flowers treated with the phytohormone ethylene, which induces premature senescence (Woodson and Lawton, 1988). To analyze these changes further, cDNAs were isolated from a library constructed using mRNAs from senesting carnation flower petals (Lawton et al., 1989). The approach used to isolate these senescence-related cDNAs involved differential hybridization (Fig. 3). The selected cDNAs represent genes that increase in expression during the senescence of carnation petals (Fig. 4). The increase in senescence-related mRNA level during senescence is at least partially due to increased gene transcription (Lawton et al., 1990; Woodson et al., 1990). These senescencerelated genes are expressed specifically in senescing flowers and show no evidence of expression in other organs of carnation. While the function of these genes is unclear, the pattern of their expression indicates a role in senescence. The insertion and expression of antisense senescence-related genes in carnation may give some clues as to the function of the proteins these genes encode. More recently, we have isolated cDNA clones representing mRNAs for a putative ethylene-forming enzyme (Wang and Woodson, 1991) and 1-aminocyclopropane-1-carboxylate synthase (K.Y. Park and W.R. Woodson, unpublished results). Expression of antisense mRNAs for these enzymes should effectively block ethylene biosynthesis and inhibit flower senescence. We have developed an Agrobacterium -mediated transformation system for carnation that will allow us to test this strategy for altering petal senescence.

\section{CONCLUSION}

Recent developments in plant molecular biology open the way for unprecedented opportunities to use the techniques of genetic engineering for the improvement of flower crops. I have attempted to review a few exciting areas of current research activity that undoubtedly will be put to practical use with our crops. Research on several traits of specific importance to the flower industry, such as flower longevity and flower color, is nearing the stage of applying genetic engineering for their improvement. It should also be noted that in addition to the application of molecular biology to crop improvement, we are witnessing the use of this technology to understand plant growth and development as never before. At the very least, this is as important as our goals of crop improvement. The ability to selectively mutate genes of known and unknown function using antisense RNA (van der Krol et al., 1988) and to alter endogenous hormone levels using the T-DNA genes of Agrobacterium (Klee et al., 1987; Medford et al., 1989) offers exciting possibilities for the control of plant development. As horticultural scientists, we should not wait for developments in molecular biology to reach the stage of application, but, rather, initiate research programs to begin to address questions of fundamental importance to the efficient, cost-effective, and environmentally sound production of our crops.

\section{Literature Cited}

Abel, P.P., R.S. Nelson, B. De, N. Hoffmann, S.G. Rogers, R.T. Fraley, and R.N. Beachy. 1986. Delay of disease development in transgenic plants that express the tobacco mosaic virus coat protein gene. Science 232:738-743.

Borochov, A. and W.R. Woodson. 1989. Physiology and biochemistry of flower petal senescence. Hort. Rev. 11:15-43.

Broekaert, W.F., J. van Parijs, F. Leyns, H. Joos, and W.J. Peumans. 1989. A chitin-binding lectin from stinging nettle rhizomes with antifungal properties. Science 245:1100-1102.

Broglie, K.E., P. Biddle, R. Cressman, and R. Broglie. 1989. Functional analysis of DNA sequences responsible for ethylene regulation of a bean chitinase gene in transgenic tobacco. Plant Cell 1:599-607.

Chang, C., J.L. Bowman, A.W. DeJohn, E.S. Lander, and E.M. Meyerowitz. 1988. Restriction fragment length polymorphism linkage map for Arabidopsis thaliana. Proc. Natl. Acad. Sci. USA 85:6856-6860.

Coen, E.S. and R. Carpenter. 1986. Transposable elements in Antirrhinum majus: Generators of genetic diversity. Trends Genet. 2:292-296.

de Vlaming, P., A. Cornu, E. Fracy, A.F.M. Gerats, D. Maizonnier, H. Wiering, and H.J.M. Wijsman. 1984. Petunia hybrida: A short descrip- tion of the action of 91 genes, their origin and their map location. Plant Mol. Biol. Rpt. 2:21-42

Dooner, H.K. 1983. Co-ordinate genetic regulation of flavonoid biosynthetic enzymes in maize. Mol. den. Genet. 189:136-141.

Feldmann. K.A.. M.D. Marks. M.L. Christianson. and R.S. Quatrano. 1989. A dwarf mutant of Arabidopsis generated by T-DNA insertion mutagenesis. Science 243:1351-1354.

Fischhoff, D.A., K.S. Bowdish, F.J. Perlak, P.G. Marrone, S.M. McCormick, J.G. Niedermeyer, D.A. Dean, K. Kusano-Kretzmer, E.J. Meyer, D.E. Rocheiter, S.G. Rogers, and R.T. Fraley. 1987. Insect tolerant transgenic tomato plants. Bio/Technology 5:807-812.

Gasser. C.S. and R.T. Fraley. 1989. Genetically engineering plants for crop improvement. Science 244:1293-1299.

Halevy, A.H. and S. Mayak. 1979. Senescence and postharvest physiology of cut flowers, part 1. Hort. Rev. 1:204-236.

Halevy, A.H. and S. Mayak. 1981, Senescence and postharvest physiology of cut flowers, part 2. Hort. Rev. 3:59-143.

Hilder, V.A., A.M.R. Gatehouse, S.E. Sheerman, R.F. Barker, and D. Boulter. 1987. A novel mechanism of insect-resistance engineered into tobacco. Nature (London) 330:160-163.

Hoekema, A,, M.J. Huisman, L. Molendijk, P.J.M. van den Elzen, and B.J.C. Cornelissen. 1989. The genetic engineering of two commercial potato cultivars for resistance to potato virus X. Bio/Technology 7:273278.

KIee, H.J., R.B. Horsch, M.A. Hinchee, M.B. Hein, and N.L. Hoffmann. 1987. The effects of overproduction of two Agrobacterium tumefaciens T-DNA auxin biosynthetic gene products in transgenic petunia plants. Genes Dev. 1:86-96.

Klee, H., R. Horsch, and S. Rogers. 1987. Agrobacterium -mediated plant transformation and its further application to plant biology. Annu. Rev. Plant Physiol. 38:467-486.

Lawton, K.A., B. Huang, P.B. Goldsbrough, and W.R. Woodson. 1989. Molecular cloning and characterization of senescence-related genes from flower petals. Plant Physiol. 90:690-696.

Lawton, K.A., K.G. Raghothama, P.B. Goldsbrough, and W.R. Woodson. 1990. Regulation of senescence-related gene expression in carnation flower petals by ethylene. Plant Physiol. 93:1370-1375.

Lay-Yee, M., R.M. Sachs, and M.S. Reid. 1987. Changes in cotyledon mRNA during floral induction of Pharbitis nil strain violet. Planta 171:104109.

Martin, C., R. Carpenter, B.S. Loen, and A.T.M. Gerats. 1987. The control of floral pigmentation in Antirrhinum majus, p. 19-52. In: A. Thomas and D. Grierson (eds.). Developmental mutants of higher plants. Cambridge University Press, Cambridge, U.K.

McCabe, D.E., W.F. Swain, B.J. Marinell, and P. Christou. 1988. Stable transformation of soybean (Glycine max) by particle acceleration. Bio/ Technology 6:923-926.

McDaniel, C.N. 1980. Influence of leaves and roots on meristem development in Nicotiana tabacum L. Planta 148:462-467.

McPherson, S.A., F.J. Perlak, R.L. Fuchs, P.G. Marrone, P.B. Lavrik, and D.A. Fischhoff. 1988. Characterization of the coleopteran-specific protein gene of Bacillus thuringiensis var. tenebrionis. Bio/Technology 6:61-66.

Medford, J.I., R. Horgman, Z. El-Sawi, and H.J. Klee. 1989. Alterations of endogenous cytokinins in transgenic plants using a chimeric isopentenyl transferase gene. Plant Cell 1:403-413.

Meeks-Wagner, D.R., E.S. Dennis, K. Tran Thanh Van, and W.J. Peacock. 1989. Tobacco genes expressed during in vitro floral initiation and their expression during normal plant development. Plant Cell 1:25-35.

Meyer, P., I. Heidmann, G. Forkmann, and H. Saedler. 1987. A new petunia colour generated by transformation of a mutant with a maize gene. Nature (London) 330:667-678.

Meyerowitz, E.M. 1989. Arabidopsis, a useful weed. Cell 56:263-269.

Nam, H., J. Giraudat, B. den Boer, F. Moonan, W.D.B. Loos, B.M. Hauge, and H.M. Goodman. 1989. Restriction fragment length polymorphism linkage map of Arabidopsis thaliana. Plant Cell 1:699-705.

O'Neill, S.D. 1989. Molecular analysis of floral induction in Pharbitis nil, p. 19-28. In: E. Lord and G. Bernier (eds.). Plant reproduction: From floral induction to pollination. Amer. Soc. Plant Physiol. Ser. vol. I.

Schell, J. 1987. Transgenic plants as tools to study the molecular organization of plant genes. Science 237:1176-1183.

Schlumbaum, A., F. Mauch, U. Vogeli, and T. Boller. 1986. Plant chitinases are potent inhibitors of fungal growth. Nature (London) 324:365367.

Schwartz-Sommer, Z., N. Shepherd, E. Tacke, A. Gierl, W. Rohde, L. Leclercq, M. Mattes, R. Berndtgen, P.A. Peterson, and H. Saedler. 1987. Influence of transposable elements on the structure and function of the AI gene of Zea mays. EMBO J. 6:287-294.

Tran Thanh Van, M. 1973. Direct flower neoformation from superficial tissue of small explants of Nicotiana tabacum L. Planta 148:462-467.

Turner, N.E., K.M. O’Connell, R.S. Nelson, P.R. Sanders, R.N. Beachy, 
R.T. Fraley, and D.M. Shah. 1987. Expression of alfalfa mosaic virus coat protein gene confers cross-protection in transgenic tobacco and tomato plants. EMBO J. 6:1181-1188.

Vaek, M., A.S. Reynaerts, H. Hofte, S. Jansens, M. de Beucketer, C. Dean, M. ZaBeau, M. van Montagu, and J. Leemans. 1987. Transgenic plants protected from insect attack: Nature (London) 328:33-37.

van der Krol, A.R., P.E. Lenting, J. Veenstra, I.M. van der Meer. R.E. Koes, A.G.M. Gerats, J.N.M. Mol, and A.R. Stuitje. 1988. An antisense chalcone synthase gene in transgenic plants inhibits flower pigmentation. Nature (London) 333:866-869.

Vince-Prue, D. and J. Gressel. 1986. Pharbitis nil, p. 47-81. In: A.H Halevy (ed.). Handbook of flowering. vol. IV. CRC Press, Boca Raton, Fla.

Wang, H. and W.R. Woodson. 1991. A flower senescence-related mRNA from carnation shares sequence similarity with fruit ripening-related mRNAs involved in ethylene biosynthesis. Plant Physiol. (In press.)

Woodson, W.R. 1987. Changes in protein and mRNA populations during carnation petal senescence. Physiol. Plant. 71:445-502.

Woodson, W.R. and A.K. Handa. 1987. Changes in protein patterns and in vivo protein synthesis during presenescence and senescence of hibiscus petals. J. Plant Physiol. 128:67-75.

Woodson, W.R. and K.A. Lawton. 1988. Ethylene-induced gene expression in carnation petals. Relationship to autocatalytic ethylene production and senescence. Plant Physiol. 87:478-503.

Woodson, W.R., K.A. Lawton, R.C. Meyer, Jr., K.G. Raghothama, and P.B. Goldsbrough. 1990. Regulation of gene expression in senescing carnation petals, p. 203-212. In: A.B. Bennett and S.D. O'Neill (eds.). Horticultural biotechnology, Wiley-Liss, New York. 